\title{
Eenige aanteekeningen over de land- en zoetwater- molluskenfauna van Nederland
}

\author{
DOOR \\ JOHANNA SGHOLTEN, \\ Bibliothecaresse van het Kon. Zoologisch Genootschap „Natura Artis Magistra”.
}

In 1915 vormde zich een comité, dat zich ten doel stelde; de molluskenfauna van Nederland te bestudeeren. Om dit doel te bereiken, is het begonnen, alle betrouwbare vondsten uitvoerig te catalogiseeren en jaarlijks een lijst van vindplaatsen samen te stellen.

Aan de hand van deze lijst willen wij hier eenige aanteekeningen geven.

Vergelijken we de vondsten, die daarop voorkomen met de Duitsche fauna, dan wordt de meening, dat onze land- en zoetwatermolluskenfauna in hoofdzaak ${ }^{1}$ ) een voortzetting is van die der Noordduitsche laagvlakte, volkomen bevestigd.

Slechts één soort ${ }^{2}$ ) komt op onze lijst voor, die in Duitschland ontbreekt, en dit is nog een brakwatervorm, nl. Dreissensia cochleata Kickx.

Deze lamellibranchiaat werd in 1835 door van Haesendonck in de Schelde bij Antwerpen gevonden, waar ze in grooten getale op 't houtwerk van de haven bevestigd was, tusschen Balanus e. a. ${ }^{3}$ )

Sedert dien werd ze herhaalde malen op deze klassieke vindplaats geconstateerd bovendien nog op andere vindplaatsen in het Noordwestelijk deel van België, nl.

1. Op 't strand te Ostende, levend tusschen marine planten door Colbeau ${ }^{4}$ );

2. in het brakke water van 't Kanaal van Bergen naar Duinkerken ${ }^{5}$ );

3. te Brussel tusschen waterplanten uit 't Kanaal van Brussel naar Charleroi ${ }^{\circ}$ );

4. in een' plàs in de Scheldepolder, drooggelegd bij 't graven van een kanaal bij den aanleg van het Amerikadok te Antwerpen (morts, mais en bon état de conservation) ${ }^{7}$ ).

In later jären schijnt ze in de haven van Antwerpen minder talrijk te zijn geworden. Raeymaekers en De Loë zeggen tenminste ${ }^{8}$ ): "Malgré de nombreuses recherches faites par différents malacologistes cette espèce n'a plus été constatée à Anvers."

In Nederland werd ze in 1895 het eerst gevonden door R. F. Maitland.

Op de vergadering der Nederl. Dierk. Vereeniging van $27^{\prime}$ Maart $189^{\prime \prime}$ deelt de Secretaris mede, dat bij hem is ingekomen een doosje met kleine brakwatermossels uit den Amstel,

1) Ook Noord-Frankrijk en België komen in aanmerking.

2) De Heer-Schepman waz zoo vriendelijk, mij mede te deelen, dat Xerophila virgata D. C. in Noord-Holland gevonden moet zijn. Zoover wij weten, komt deze soort niet in Duitschland voor.

Wellicht uit Engeland af komstig.

3) Bull. Ac. Belgique II, 1835.

4) Ann. Soc. Mal. Belgique I, 1865, III, 1868.

5) Guerne, J. de, Journal de Conchyl. XXII, 1874

6) Dautzenberg, Ph. Ann. Soc. Mal. Belgique, Bull. des Séances 2 Août. 1868.

7) Raeymaekers et De Loë. Ann. Soc. Mal. Belgique XX, p. XXVIII, 1885.

8) Bull. Soc. Mal. Belgique XX. 
nabij den Omval. De Heer Maitland maakt er opmerkzaam op, dat dit een belangrijke vondst is, daar ze tot een vorm behooren, die oorspronkelijk uitsluitend aan Noord-Amerika eigen schijnt te zijn. Daarbij haalt hij enkele van de bovengenoemde vindplaatsen aan en spreekt als zijn vermoeden uit, dat ze ook wel op andere plaatsen in ons vaderland in brakke wateren zullen voorkomen.

Dit vermoeden wordt door onze lijst bevestigd. Daarop wordt ze vermeld van:

1. Schoten 1915. Westoever van het Noorderspaarne.

2. Petten 1915. Eindpunt der Hondsbossche vaart bij de zeewering.

Bovendien werd ze op de oorspronkelijke vindplaats in den Amstel nog herhaaldelijk geconstateerd.

Eigenaardig is de verspreiding van enkele soorten, die zoowel in Noord-Duitschland als in Nederland zeldzaam zijn, en uit welker verspreiding men zou mogen opmaken, dat ze eerst sedert kort naar deze streken verhuisd zijn.

Zooals :

A. Hydrobia jenkinsi E. A. Smith.

In Engeland reeds sedert 1889 bekend, waar Jenkins ze voor het eerst aantrof langs den oever van de Thames nabij Plumstead ${ }^{1}$ ). Hij zond ze op naar het British Museum, waar Smith ze niet alleen nieuw voor de. fauna, maar aanvankelijk ook nieuw voor de wetenschap verklaarde.

Later rees er bij Canon Norman een vermoeden op over de identiteit van deze Hydrobia met Paludina crystallina Pfeiff. var. coronata Pfeiff., een West-Indische soort, die een rij stekels vertoont op de plaats, waar. Hydrobia jenkinsi dikwijls een kiel draagt.

$\mathrm{Na}$ deze vondst van Jenkins werd $\mathrm{H}$. jenkinsi herhaaldelijk gesignaleerd in Engeland. In 1893 ook in Ierland.

Adams ${ }^{1}$ ) heeft de eerste drie vindplaatsen in Engeland vergeleken en komt tot de ontdekking, dat dit groote houthavens zijn, of in recenten tijd waren. Hij heeft toen nog andere houthavens onderzocht, en trof ze ook werkelijk in enkele daarvan aan, of in de wateren, die onmiddellijk met deze havens in verbinding staan.

Adams kwam toen tot de hypothese, dat $\mathrm{H}$. jenkinsi indigeen zou zijn aan de lage kusten van Rusland of Finland. Mocht deze Hydrobia werkelijk identisch blijken te zijn met de bovengenoemde Paludina (nu Amnicola), dan sluit Adams nog de mogelijkheid niet uit, dat ook Paludina niet indigeen in W.-Indië is, maar daarheen met Baltisch hout versleept werd.

In 1898 vond J. N. Milne. ${ }^{2}$ ) ze levend in een licht brakke plas nabij Culmore Station (Derry), waarvan meer dain 50\% gekield. Welch ${ }^{2}$ ) zegt hiervan: „many of these are distinctly coronated rather than carinated, the crown of spines having a tendency to run into a fine keel in the final whorl."

Naar aanleiding van een vondst in zoet water, nabij Newry (Down) ${ }^{3}$ ), waar alle exemplaren ongekield waren, stelt Welch de vraag: "Is it possible that the carination increases with the amount of salt water present?" en hij verwijst hier naar de vondsten van Milne ${ }^{2}$ ) op twee verschillende plaatsen in de Toyle (Donegal). Nabij Carrigans waren er onder 800 exemplaren ${ }^{4}$ ), die bij onderzocht, $5 \%$ gekield; nabij Johnstone (where the river is practically fresh. Welch $\left.{ }^{2}\right)$ ) vertoont geen enkel exemplaar een kiel.

Vergelijken we nu de vondsten in Nederland:

1. Voor 't eerst gevonden 25 Jan. 1913 in een slootje bij Amsterdam, aan den overkant van 't IJ, binnendijks. 't Slootje was dien dag met een lichte ijskorst bedekt. De kleine slakken lagen daar in groote hoeveelheid op den bodem in gezelschap van Hydrobia stag-

1) Adams L. E., The Irish Naturalist VI, p. 234, 1897.

2) Welch, R. The Irish Naturalist VII, 1898, p. 150.

3) —-, ibid., p. 271

4) "He found several large patches of living and dead shells collected together, one of these six yards long, one yard wide, and one to two inches deep." 
nalis Bast., Limnaea palustris 0. F. Müll. en Limnaea ovata Drap. Hieronder was geen enkel gekield exemplaar.

2. Diemerbuitendijksche polder, 1915 slootje, buitendijks, zeer ondiep. Met Hydrobia stagnalis Bast. 93 exemplaren, waaronder geen enkel gekield exemplaar. Dit water moet brak zijn.

3. Petten, 1915 eindpunt der Hondsbossche vaart bij de zeewering, met Dreissensia cochleata Kickx en Neritina fluviatilis L. 281 exemplaren, waarvan $40 \%$ meer of minder gekield (sommige slechts heel flauw). Chloorgehalte van het water 3105 mgr. p. L.

4. Schoten, 1915, Westoever van het Noorderspaarne met Dreissensia cochleata Kickx, Neritina fluviatilis L., Limnaea ovata Drap. en Physa fontinalis L. 321 exemplaren, waarvan $40 \%$ meer of minder gekield.

5. Vlissingen, 1918, zonder nadere opgave. Geen gekielde vormen.

6. Schoondijke, 1918, in een kreekje, dichtbij een duiker. \pm 9000 exemplaren, ongekield.

Voor zoover wij. weten, werd Hydr. jenk. in Duitschland slechts éénmaal aangetroffen en wel in Warnemünde.

B. Musculium ryckholti Norm.

Thiele ${ }^{1}$ ) zegt onder Sphaerium (Musculium) lacustre 0. F. Müller „Eine Form mit stärker hervorragenden Wirbeln wird als S. (M.) Rykholtii Normand unterscheiden, es ist aber noch zweifelhaft, ob diese französische Art wirklich in Deutschland vorkommt".

In 1910 werd deze soort(?) te Acht in Noord-Brabant gevonden.

In 1918 bij Voorst en bij Twello.

De jonge exemplaren van deze laatste vondst doen denken aan de var. steini A. Schm. van Musculium lacustre 0. F. Müll., 't geen de Heer Schepman doet opmerken: Thiele heeft misschien gelijk, door slechts één soort aan te nemen.

C. Zonitoides excavatus Bean.

In Engeland vrij algemeen.

In den Census of the Britisch Land- and Freshwater Mollusca 1902 geeft L. E. Adams haar als Hyalinia excavata op voor 8 counties (Taylor in zijn Monogr. der Land- en zoetwaterslakken van Gr. Britt. en Ierl. 9) in Ierland; en voor 6 (Taylor 11) in Schotland. Bijna al deze counties liggen langs de kust of langs de Firth of Lorne.

In Engeland is ze, behalve in vele kuststreken, ook ruim in het binnenland vertegenwoordigd.

Eigenaardig is nu onze eenige vondst op een zeer afgelegen plekje in Drente, in de gemeente Anloo, westelijk van den zandweg van Gasteren naar Marke van Eext. Ze kwam daar vrij talrijk voor onder dorre blaren op een ruig stukje kreupelhout met Quercus, Alnus, Salix, Sorbus, Ilex, Betula, waartusschen Hedera, Ajuga, Rubus, Oxalis e: a.

Uit den driehoek Assen-Gieten-Zuidlaren, werd ze onder 85 vondsten van mollusken slechts van dit ééne geïsoleerde plekje gerapporteerd.

De Heer Schepman deelt mij mede, dat Taylor opgeeft, dat de soort ook in Rhoon zou voorkomen volgens mededeeling van J. R. A. B. Tomlin, maar deze opgave moet sterk betwijfeld worden en berust, volgens Schepman, waarschijnlijk op verkeerde determinatie of verwisseling van etiquetten.

In Duitschland is ze, voor zoover wij weten, ook slechts eenmaal gesignaleerd en wel in Flensburg in Holstein.

In België eveneens eenmaal, reeds in 1865, door Colbeau ${ }^{2}$ ) tusschen Esschen en Calmpthout, dicht bij de Nederlandsche grens.

In tegenstelling met de. molluskenfauna van de Noordduitsche laagvlakte wijkt die van Groot Britannië en Ierland in veel opzichten van de onze af. Waar deze landen een veel

1) in. Brauer, Die Süsswasserfauna Deutschlands H. 19, 1909.

2) Colbeau, Ann. Soc. Malac. Belgique I, 1865. 
sterker afwisseling in bodem en klimaat vertoonen, was het te verwachten, dat er vele soorten gevonden worden, die in Nederland ontbreken, doch ook het omgekeerde doet zich voor. Onze lijst geeft een twintigtal soorten, die zoowel op de list ot the British Non-marine Mollusca ${ }^{1}$ ) als in den Census ontbreken.

Opvallend is hieronder 't oude geslacht Clausilia, dat in Engeland slechts 4 vertegen. woordigers heeft, n.1.

1. Clausiliastra laminata Mont.

2. Alinda biplicata Mont.

3. Kuzmicia bidentata Ström.

4. Pirostoma rolphi. Leach.

terwịl behalve deze in Nederland nog 3 soorten voorkomen, n.l.

5. Kuzmicia dubia Drap.

6. ; parvula Stud.

\%. Pirostoma lineolata Held.

Aan den anderen kant komen op de lijst voor Engeland een veertigtal soorten voor, die, voor zoover wij weten, nog niet in Nederland aangetoond werden. Hieronder zijn acht geslachten, die in ons land door geen enkele soort vertegenwoordigd worden, n.l.

1. Testacella. . . . in Engeland 3 spec.

2. Milax . . . . . " ” 2 .

1. Geomalacus (zie onder) " $" 1$ "

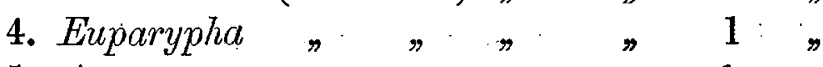

5. Azeca. . . . . " \# 1 ,

6. Ovatella (zie onder) . " ,, 1 ,

\%. Pseudaminicola . . " , 1 ,

8. Acicula . . . . » " 1 "

We moeten hierbij wel in aanmerking nemen, dat onze lijst na slechts drie jaar werken, nog verre van volledig is. Er komen 122 soorten op voor, terwijl Schepman er 160 als mogelijk opgeeft. Toch zijn er onder die 38, die misschien nog eens in ons land gevonden worden, ook weer, die in Engeland ontbreken, zoodat de verhouding daardoor niet sterk gewijzigd zou worden.

\section{Geomalacus maculosus Allman.}

In 1842 door Andrews op de rotsen van Lough Carogh in 't Z.W. van Ierland waargenomen; daarna ook in Portugal, waar Simroth e. a. nog verschillende soorten van dit belangwekkende genus vonden. Scharff ${ }^{2}$ ) noemt 't dan ook een "lusitanian element".

De Census geeft nog Norfolk en Merioneth, beiden eveneens aan de kust.

Op de vergadering der Ned. Dierk. V'ereen. van 14 Juni 1914 deelde Prof. Ritzema Bos mede, dat hij een aantal exemplaren Geomalacus maculosus Allman, die in ons land nog niet was waargenomen, van een landbouwer (den Heer J. D. Kramer te Cortgene)' ontving.

In 't Tijdschrift voor Plantenziekten XX (1914), p. 55 geeft Prof. Ritzema : Bos een uitvoeriger beschrijving van deze slak en haalt daarin een schrijven van den Heer Kramer aan, waarin laatstgenoemde spreekt van "kleine, grijsachtige slakjes" G. maculosus is echter zwart met geel gevlekt, 't geen ons op het denkbeeld bracht, of hier misschien een zeer begrijpelijke vergissing zou zijn voorgekomen.

Na een schrijven aan den Heer Kramer ontvingen wij in 1915 slechts Arion circumscriptus Johnst. (grijs met donkere zijbanden). Ook het Rijksmuseum te Leiden, dat ons nog een exemplaar ter vergelijking zond, ontving slechts Arion circumscriptus.

1) publ. by authority of the Conchol. Soc. of Great Britain and Ireland.

2) Scharff, R. F., The History of the European Fauna. London 1899: 
Prof. Ritzema Bos was zoo vriendelijk, ons dezer dagen de bewuste slakken (5 ex. op liquor) toe te zenden. Daar ze echter aanmerkelijk gecontraheerd zijn en geen vlekken meer vertoonen, alleen nog een spoor van banden, zooals die bij A. circumscriptus voorkomen, schijnt mij een determinatie naar het uitwendige voorkomen te gewaagd. De genitaalopening, die bij Geomalacus ongeveer aan de basis van den voeler moet liggen, is daar niet waar te nemen, en, om het beste kenmerk, de inwendige schelp te zien, zou een exemplaar opgeofferd moeten worden. Wat dit kenmerk betreft, schrijft de Heer Schepman mij, na bezichtiging der exemplaren: „of er een inwendige schelp voorhanden is, kan ik niet zeker vaststellen, maar bij Limax is er toch altijd wat van te zien of te bemerken, bij uitwendige waarneming; hier vind ik niets van dien aard. Wel zie ik uiterst kleine korreltjes, zooals ik die ook bij genoemden Arion. (= Arion circumscriptus Johnst.) vind".

Juist voor het ter perse gaan van deze aanteekeningen mochten wij van Prof. Ritzema Bos een exemplaar voor anatomisch onderzoek ontvangen.

Uit dit onderzoek, dat door den heer Schepman werd uitgevoerd, bleek, dat we hier inderdaad met een Arionsoort te doen hebben:

$1^{\circ}$. een inwendige schelp ontbreekt.

$2^{0}$. de middentand van de radula vertoont 3 spitsen zooals bij alle inlandsche Arionsoorten. Geomalacus heeft een éénspitsige middentand.

We kunnen Geomalacus maculosus Allm. dus voor onze fauna schrappen.

\section{Euparypha pisana Müll.}

In 1912 vonden wij een ledige schelp in een tuin aan de Weesperzijde te Amsterdam, daar ongetwijfeld met afval neergeworpen: Een onderzoek bij den kruidenier eenige huizen verder leverde mij onmiddellijk 3 leege schelpen uit een zak pinda's.

't Is dan ook buiten quaestie, dat deze vondst voor onze fauna volkomen waardeloos is.

\section{Ovatella bidentata Mont.}

Geyer noemt in zijn overigens zeer aan te bevelen determineerwerkje ${ }^{1}$ ) Ovatella bidentata Mont. een Duitsche soort. Hier schijnt echter een vergissing ingeslopen, daar de beschrijving overeenkomt met Phytia Drap. een basommatophoor uit de fam. der Auriculidae, die in 't brakke water van Engeland, Nederland en Duitschland leeft. Op onze lijst staat ze vermeld van de Zuiderzee, de Waddenzee en de Oosterschelde.

Voor zoover wij weten is Ovatella bidentata Mont. noch in Nederland, noch in Duitschland aangetroffen.

1) Geyer, Unsere Land- u. Süsswasser-Mollusken. 2te Aufl. 1909. 